\title{
Estimating Competitiveness Relations between Firms of a Multinational Group of Clothing and Footwear Manufacturing Industry in Greece
}

\author{
Christos Konstantinidis*, Anastasia Tsolaki, Nikolaos Giovanis \\ International Hellenic University, School of Business Administration, Serres, Greece \\ Email: *chkons10@gmail.com, tsolakinat@yahoo.gr,ng@ihu.gr
}

How to cite this paper: Konstantinidis, C., Tsolaki, A., \& Giovanis, N. (2021). Estimating Competitiveness Relations between Firms of a Multinational Group of Clothing and Footwear Manufacturing Industry in Greece. Theoretical Economics Letters, 11, 789-802.

https://doi.org/10.4236/tel.2021.114051

Received: July 6, 2021

Accepted: August 28, 2021

Published: August 31, 2021

Copyright $\odot 2021$ by author(s) and Scientific Research Publishing Inc. This work is licensed under the Creative Commons Attribution International License (CC BY 4.0).

http://creativecommons.org/licenses/by/4.0/

\begin{abstract}
The footwear and clothing manufacturing sector is one of the most vibrant and profitable sectors in Greece. The majority of the firms belonging to this sector present important figures in terms of sales, turnover and value added and are part of multinational firms. For that reason the objective of this paper is to estimate and compare the competitiveness of two firms, specifically Bershka and Zara, parts of the group Inditex, with the use of financial ratios such as liquidity, capital structure etc. The results show that the comparison between the two specific firms with the largest market share in the group can lead to safe proposals and commitments for the improvement of the competitiveness of the group.
\end{abstract}

\section{Keywords}

Financial Ratios, Footwear and Clothing Industry, Competitiveness, Greece

\section{Introduction}

In a fluid international financial environment, the clothing and footwear sector according to the available financial data of Infoban Hellastat is one of the most important export sectors for the Greek economy, showing a growth in important economic figures such as turnover, exports and value added. With the majority of the companies in Greece, being imported and less productive, although in some cases a combination is observed, as well as large multinationals confirming their trust in Greek subsidiaries, the majority of clothing and footwear companies using all of the available tool tries to choose the most appropriate strategy to stimulate its competitiveness, which will ensure its viability and its further presence in the markets. 
On the other hand, the concept of competitiveness is generally accepted as a wide concept, which is often difficult to be defined and measured precisely (Fischer \& Schroneberg, 2007). For this reason, a great part of the literature has been concerned with which is the most effective way of measuring it and the effect of certain economic factors for the development of strategies enhancing it such as the use of brand names (Vrontis et al., 2018). Lucena, et al. (2020), studied the importance of human factor to increase the level firm competitiveness. The results show that the basic skills required by the employees are important in defining short-term, medium-term and long-term business guidelines and as result increasing the firm competitiveness. Vrontis et al. (2020) summing up the existing literature in Cause related Marketing and its Implications on Competitiveness concluded that the Cause Related Marketing consists of a strategy which improves competitiveness in international level highlighting also the important role of factors such as brand name, innovation etc.

Scorrano et al. (2019) studied the online branding as a strategic tool for competitiveness in wine tourism, concluding that web provides a framework enhancing brand name and brand identity, which are crucial factors for improving competitiveness. Madushanka and Jathurika (2018) analyzed the importance of liquidity that greatly contributes to the growth and competitiveness of a firm. They concluded that the liquidity ratios (Quick ratio) have a positive impact and are significantly related to corporate profitability and competitiveness. Ganiyu et al. (2018), making a literature review analysis on the combination of financial and non-financial measurements of firms, resulted in the success of a firm is related with the implemented strategies. Also a combination of financial and non-financial measures should be complemented for the identification of firm competitiveness.

Marques et al. (2017) examined the competitiveness of footwear and clothing processing industry in Portugal, applying Michael Porter's theory. From the results occurred that innovation and product differentiation constitute strategies for improving firm competitiveness. Tsoukatos et al. (2017) analyzed the determining export factors of Greek companies in the field of clothing and footwear. The analysis of the sample showed that the industry strengthens, by focusing on factors such as age, profitability and liquidity, which have a positive effect on competitiveness, especially in the post-crisis period. Therefore, it is necessary a focus on management and marketing organization and administration.

Ramachandran and Madhumathy (2016) maintain that the best measure of a firm competitiveness is profitability because without it, it cannot grow, and as a result its stock will tend to go down. An increase in profits is the best indication that a company can pay dividends and that the share price will rise. From their results occured that with the use of indicators, a healthy capital structure that reflects a low level of debt and a corresponding high level of equity is a very positive sign of investment.

Dima and Dobrin (2016) studied the competitiveness of European textile and 
clothing industry under the influence of globalization and recent economic crisis. Using turnover, number of employees, domestic consumption, imports and exports as competitiveness indexes concluded that competitiveness of textile and clothing industry fell significantly causing restructuring and downsizing.

Summing up the existing literature there are two main ways to measure competitiveness. The first one is mainly expressed by Michael Porter aiming to the creation of competitive advantage against the competitors while the second one is based on the creation of measurable economic indexes. Michael Porter (1985), in his book "Competitive Advantage", raises the well-known Porter's Five Diamond according to which the enterprise has to be aware of the intensity of the competition in the sector in which operates. This intensity is defined and formed by the following five factors: the threat of the new entrants, the threat of the substitutes, the bargaining power of the suppliers and customers and finally the rivalry among the existing competitors.

In the present research we selected the second way with the use of financial ratios. Undoubtedly, the analysis of an individual index cannot give a complete picture of the financial position of a company, so it is necessary to compare it with other standard indicators or to correlate it with the corresponding indicators of a series of previous uses which is important both for academics and policy makers.

For the reasons referred above the purpose of this study is to determine competitiveness using financial ratios of the two largest clothing and footwear companies of a multinational group operating in Greece with the largest market share in the industry. In the following sections, the clothing and footwear sector in Greece is presented with its main characteristics as well as the two under study companies. Afterwards is the research methodology, the results of the research and the comparison between them, while the present work closes with the presentation of its conclusions and suggestions for further research.

The clothing and footwear industry in Greece

The clothing and footwear industry is one of the most important business industries in the world, with a huge contribution to the primary, secondary and tertiary sectors. The fashion sectors, as mentioned (Clothing-Textiles-Footwear), are key areas of activity of the Greek economy. They employ 80.000 employees in productive activities while also offering employment in related sectors (advertising, exhibitions, transportation, logistics, etc.) (available at: https://www.businessdaily.gr).

From 2013 onwards, with the exception of 2015, due to capital controls garment exports to Greece increased, reaching a $25 \%$ total increase from the 2017-2019 period. The positive course of the clothing sector is evidenced by exports which have increased by $26 \%$ in the three-year period 2016-2018. However, in the domestic market, the consumption of clothing remains stagnant and a national intervention plan is required which will aim at further increasing exports, improving the competitiveness of companies and tackling the domestic 
crisis. This may happen due to the fact that the existence of a previous unstable economic environment has a negative influence on the consumers' behavior who do not consider necessary the supply of these products.

After the cancellations of foreign orders and the general closure of the market, in the context of state care, to deal with the pandemic, the biggest problem that fashion companies were asked to face, after the wage costs, was liquidity (available at: https://www.businessdaily.gr). The outbreak of the pandemic has overturned consumer habits while forced closure and curfew have brought e-commerce to the forefront, setting new foundations and becoming one of the most emerging economic sectors. In April 2020, there was an increase of $171 \%$ in e-sales compared to the same period last year, while 2019, B2C e-sales generated 5.8 billion euros. It is obvious that regardless of the course of the pandemic, the shift to e-commerce is now a conscious choice and its further consolidation is a one-way street (available at: https://www.naftemporiki.gr).

Presentation of the Inditex group

INDITEX, one of the largest fashion retailers in the world with eight brands (Zara, Bershka, Pull \& Bear, Stradivarius, Massimo Dutti, Oysho, Zara Home, Uterque) and sales in 216 markets through the online platform or through 7000 stores with 175.000 employees in 202 markets, holds the lead in "Fast Fashion" clothing and footwear. It is noteworthy that all INDITEX brands are organized as separate strategic business units with the result that each company is responsible for strategy, planning, procurement and any other necessary operations it decides to follow. Decisions are highly decentralized while the company culture is horizontal, with hierarchies and formalities being minimized, so the group acts almost like a huge SME (Small and Medium-sized Enterprise).

The specially designed software used by the distribution centers ensures 24 hours delivery for stores in Europe and 48 hours for America and Asia, while the corresponding time for the main competitors is about six weeks. Another advantage of the group is the installation of a Just In Time (JIT) system, a management strategy that aligns raw material orders from suppliers directly with production programs. In this way, efficiency increases, waste is reduced, since only the goods needed for the production process are received, thus reducing the cost of inventory. Thus, the group manages to close the seasons with zero stock and achieves cheaper and more competitive prices on the products.

Every profitable business knows that in order to continue its growth it must not be complacent. This is exactly the philosophy of the group realized in the strategic move of the expansion of the activities in the e-commerce. Revenue from online sales increased by $27 \%$, reaching 3.2 billion euros in the fiscal year 2019. In addition, technologies such as augmented reality and holograms or robotics already used in some stores to deliver customers online their orders, are consolidated while at the same time the group has managed to develop a model that can change with the change of the scale of its activities and this helps it significantly in supporting its expansion in digital retail. In this context, the group 
announced that all its brands will be available online worldwide by 2020 (available at: https://www.inditex.com). Following below in Figure 1 the net sales of the Inditex group worldwide in for the 2013-2020 period is presented.

\section{Methodology.}

Financial analysts, using ratios, can be informed about the liquidity, profitability, activity and viability of a company in relation to its capital structure and have an overall picture of its financial situation (Delen et al., 2013). The types of analysis are:

- Horizontal or Diachronic or Comparative Analysis

- Trend Analysis

- Vertical Analysis or Common Size Analysis

- Numerical Analysis (Coelli et al., 1999)

As has been widely reported, companies use a variety of methods to measure their performance in order to remain competitive and profitable. Financial ratios are one of the most common ways for a business to determine if and how effective its management is and to correct any mistakes or change its strategy in order to always improve its competitiveness.

In this work, four categories of indicators were selected, for the financial years 2016-2019, of the two most competitive companies of the group, namely Zara and Bershka. These indicators examine the financial performance of the company in terms of profitability, liquidity and management of its assets. The collected data are figures of the financial statements and published balance sheets of the aforementioned companies (Tuvadaratragool, 2012). More specifically, the following categories of indicators were evaluated:

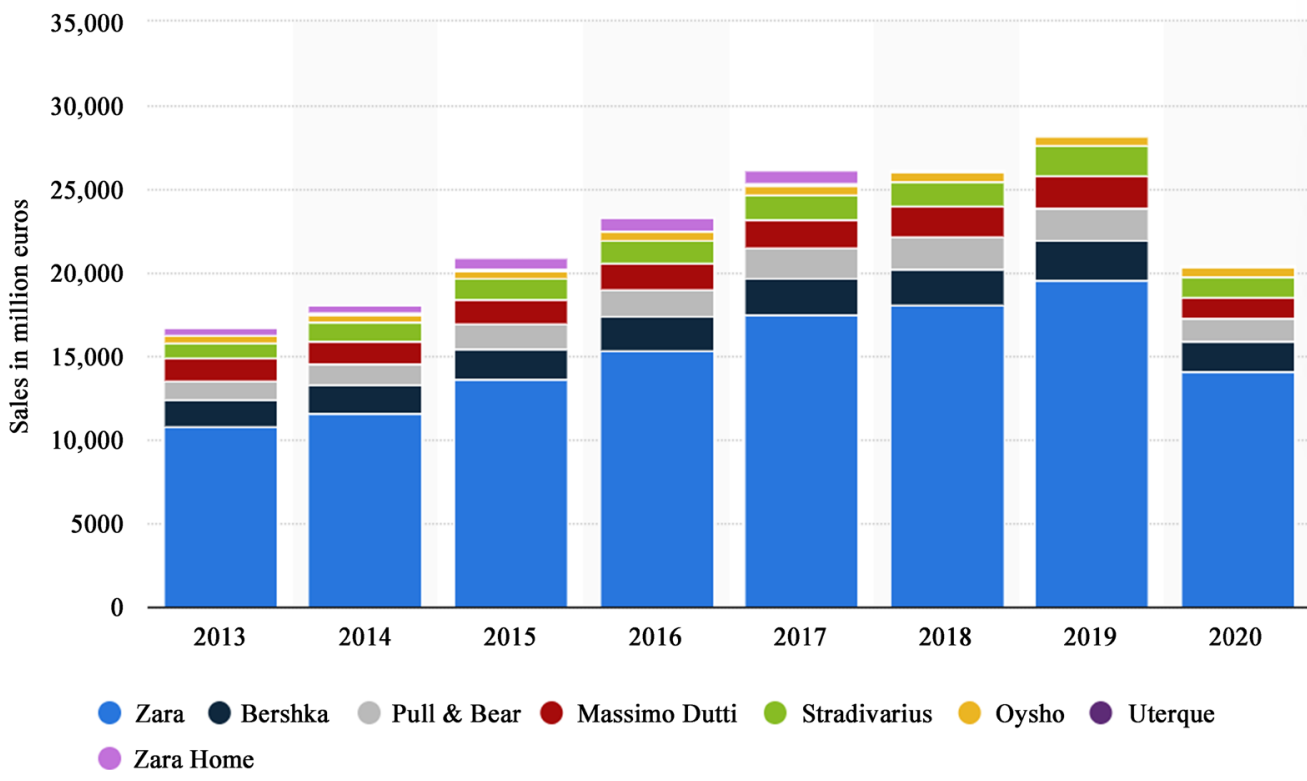

Source: https://www.statista.com.

Figure 1. Net sales of the Inditex group worldwide in the years 2013-2020. 
- Liquidity Indicators

- Activity Indicators

- Efficiency Indicators

- Capital Structure Indicators

\section{Results}

\subsection{Liquidity Ratios}

Liquidity ratios show the short-term financial position of a company as well as its ability to meet its short-term liabilities. This liquidity must come from sufficient liquid assets that are created through daily conversion (inventories $\rightarrow$ sales $\rightarrow$ receivables $\rightarrow$ cash).

\begin{tabular}{ccccc}
\hline $\begin{array}{c}\text { LIQUIDITY RATIOS } \\
\text { BERSHKA }\end{array}$ & $\mathbf{3 1 / 0 1 / 2 0 1 7}$ & $\mathbf{3 1 / 0 1 / 2 0 1 8}$ & $\mathbf{3 1 / 0 1 / 2 0 1 9}$ & $\mathbf{3 1 / 0 1 / 2 0 2 0}$ \\
\hline CURRENT RATIO & 1.34 & 1.14 & 0.76 & 0.82 \\
ACID TEST/LIQUIDITY RATIO & 0.82 & 0.71 & 0.31 & 0.37 \\
IMMEDIATE CASH RATIO & 0.76 & 0.63 & 0.23 & 0.32 \\
\hline & & & & \\
\hline LIQUIDITY RATIOS & $31 / 01 / 2017$ & $31 / 01 / 2018$ & $31 / 01 / 2019$ & $31 / 01 / 2020$ \\
ZARA & 0.87 & 0.98 & 1.15 & 1.18 \\
CURRENT RATIO & 0.57 & 0.71 & 0.81 & 0.93 \\
ACIDTEST/LIQUIDITY RATIO & 0.49 & 0.65 & 0.75 & 0.84 \\
\hline IMMEDIATE CASH RATIO & & &
\end{tabular}

Current Ratio: This ratio shows the liquidity measure but also the safety margin maintained by the company's management in order to deal with any undesirable development in the flow of working capital. The higher the index $(\geq 1)$, the more liquidity the company has. However, if it is too large, the company may not use its available financial resources properly (large inventory) so it doesn't enlarge (Grigorakos, 2009).

Bershka results: From the above results of the brand Bershka it is obvious that the liquidity of the company is at very satisfactory levels since it manages to repay its short-term liabilities almost entirely through its current assets.

Zara results: The same goes for the company's flagship. The steady upward trend of the index shows the company's policy to keep the speed of inventories and receivables at the highest possible point to ensure the necessary safety limits.

Acid Test/Liquidity Ratio: This ratio measures the ability of a company to meet its short-term assets with its most liquid assets, as it does not include Inventories in Current Assets, thus showing the direct relationship of the most liquid assets. Basically, it is a stricter measure of a company's ability to meet its short-term liabilities while assessing the potential for additional lending (Evans \& Lindsay, 2008).

Zara results: Based on the occurred results, the company Zara has an upward 
trend, which proves that, in case of immediate need, the liquidity of the company is at satisfactory levels as it keeps its cash levels at a high and stable level.

Bershka results: On the contrary, at Bershka, the index is decreasing, revealing a possible inability of the company to repay its short-term liabilities, but also a large storage which doesn't allow the easy and immediate liquidation of the Current Assets.

Immediate Cash Ratio: This ratio is a measure of the extent to which current liabilities are covered by cash flows generated by the company's activities. The use of cash flow as opposed to net income is considered a more accurate measure as profits are more easily processed. The cash flow ratio expresses the ability of the company to repay its current and overdue liabilities with the cash it has and therefore it constitutes the strictest liquidity ratio. A value higher than unit $(\geq 1)$ indicates that the company has generated more cash in a period than it needs to pay off its current liabilities. On the contrary, a price lower than one $(\leq 1)$ indicates that the company has not created enough cash to cover its current liabilities. However, this is not a definitive indication of poor financial health because for example a business may have started a project that temporarily jeopardizes cash flow but makes a great reward in the future (Tuvadaratragool, 2012).

Bershka results: From the above results for Bershka, the index decreases significantly, which leads to the belief that the company may have to review its policy, as cash is distinctively reduced, in terms of the management of its traffic data, in particular to apply less storage so that it can create the appropriate levels of security.

Zara results: On the other hand, the indexes of Zara are increasing more and more reaching the unit while its cash flows are quite satisfactory, proving the correct policy and management of its data that make it the most commercial and powerful company in the group.

\subsection{Activity Ratios}

Activity ratios show how effectively a business manages its resources in order to generate sales and achieve high profits. Therefore, these indicators are formed by the relationship between the sales of a company and various assets (Zainudin \& Hashim, 2016).

\begin{tabular}{|c|c|c|c|c|}
\hline ACTIVITY RATIOS BERSHKA & $31 / 01 / 2017$ & $31 / 01 / 2018$ & $31 / 01 / 2019$ & $31 / 01 / 2020$ \\
\hline INVENTORIES TURNOVER RATIO & 8.4 & 8.8 & 8.8 & 8.9 \\
\hline RECEIVABLES TURNOVER RATIO & 145.1 & 108.5 & 87.9 & 85.7 \\
\hline TRADE CREDITORS TO PURCHASES RATIO & 4.9 & 4.2 & 3.9 & 3.7 \\
\hline ACTIVITY RATIOS ZARA & $31 / 01 / 2017$ & $31 / 01 / 2018$ & $31 / 01 / 2019$ & $31 / 01 / 2020$ \\
\hline INVENTORIES TURNOVER RATIO & 10.7 & 11 & 11 & 11 \\
\hline RECEIVABLES TURNOVER RATIO & 71.4 & 84.3 & 97 & 98.3 \\
\hline TRADE CREDITORS TO PURCHASES RATIO & 3.8 & 3.2 & 3.4 & 3.7 \\
\hline
\end{tabular}


Inventories Turnover Ratio: This indicator shows the speed with which inventories are recycled to generate a certain volume of sales in an accounting year, namely it measures the ability of the company to sell inventories quickly. Of course, the amount of inventory of a business is directly related to its sales. Knowing that inventory management has such a significant impact on the long-term success of any retail sale, it is important that the index result is as large as possible.

Bershka results: Regarding the results of the Bershka company, the index is gradually increasing to a point that does not affect the correct and fast circulation of its stocks. If we divide the total days of the year (365) by the index, we find the time that the stocks remained in the company until they were sold. In this case, the company holds the stocks for a maximum of two months, which proves the rapid actualization of sales.

Zara results: In the case of Zara, the index is comparatively larger and gradually increases over the years, while its constant level of fluctuation indicates the company's policy. The equivalent period of time that the company holds its stocks is one month and reflects the ability of the company's management to make sales at a rapid pace.

Receivables Turnover Ratio: This indicator shows how many times on average the receivables of the company are collected during the accounting year. Therefore, when the collection speed is high, the collection of the receivables of a company is even more successful. If we divide the calendar days of the year (365) by the index, we get the average time that the company has to wait after making a sale to receive cash. Trend monitoring is useful over time access the quality and liquidity of the receivables.

Bershka results: Regarding the course of the Bershka index, there is a downward trend. However, the value of the index is high and its change during the years does not dramatically affect the correct credit policy of the company (Zainudin \& Hashim, 2016).

Zara results: In contrast, in the case of Zara, the index is on the rise. With this indicator, we can calculate the rate at which a company buys and resells the products (or stocks) of its customers. Low inventory turnover can indicate poor management, poor buying practices or sales techniques as well as poor decision making. It is important to understand that low and high rates are only in relation to the specific industry or industry of the company. There is no definite number that indicates what constitutes a good or bad indicator of receivables turnover in all sectors. In this case, if the index shows an upward trend, the risk from uncertain/bad customers is reduced.

Trade Creditors to Purchases Ratio: This ratio is a liquidity ratio that measures a company's ability to pay short-term liabilities or debts within a year. More specifically, it instructs investors and analysts how a business can maximize current assets on its balance sheet to meet current debt and other liabilities. It is important to mention that the index should analyzed in relation to the industry 
average. However, because the current ratio at any given time is merely a snapshot, it does not give a complete representation of a company's liquidity or solvency. To analyze the index, analysts need to know the most common measurements used as well as the specific company factors and also the macroeconomic factors that can affect the short-term financial performance of the company.

Bershka results: Regarding the results of the company Bershka, the index should be interpreted in comparison with the receivables turnover ratio from its customers as this is the only way to see the emerging liquidity of the company and its creditworthiness. The company seems to be closely monitoring the payment period of its liabilities as the payment time of short-term liabilities is shorter than the receivables turnover time, which shows that the company tries to balance between the need to have cash and keep its suppliers gratified.

Zara results: In the case of Zara, comparing the receivables and repayment ratios of short-term liabilities, it is held the reliable credit policy of the company as it manages to pay its liabilities in a longer period of time than it collects its receivables and may have created a financing source which is an effective use of foreign capital.

\subsection{Profitability Ratios}

Profitability ratios express the ability of the company to generate profits, to operate effectively while considered whether the profits were satisfactory (Euske \& Zander, 2005). Therefore, the efficiency with which a company is run is expressed. Changes in profits must be considered in relation to the funds consumed to make them. Therefore, these indicators detect the profitability of the total assets and the main activities of each company.

\begin{tabular}{ccccc}
\hline PROFITABILITY RATIOS BERSHKA & $31 / 01 / 2017$ & $31 / 01 / 2018$ & $31 / 01 / 2019$ & $31 / 01 / 2020$ \\
\hline ROA & $12.08 \%$ & $8.5 \%$ & $3.4 \%$ & $3.9 \%$ \\
ROE & $22.4 \%$ & $16.6 \%$ & $7.4 \%$ & $7.9 \%$ \\
\hline PROFITABILITY RATIOS ZARA & $31 / 01 / 2017$ & $31 / 01 / 2018$ & $31 / 01 / 2019$ & $31 / 01 / 2020$ \\
\hline ROA & $4.7 \%$ & $4.6 \%$ & $9.2 \%$ & $9.8 \%$ \\
ROE & $10.3 \%$ & $10.6 \%$ & $20.2 \%$ & $20.7 \%$ \\
\hline
\end{tabular}

Return on Assets/ROA: The performance of a company's assets reflects the ability of management to use the company's financial resources to generate net profits. Essentially, this combined asset return ratio displays the velocity of assets and net profit (DuPont ratio). It is worth noting that the return on assets depends on two main factors 1) the net profit margin 2) the turnover speed of the assets (DuPont index). Fundamentally, ROA shows the profits generated by the assets (Neely, 2002).

Bershka results: Regarding the company Bershka, the index has a downward trend. The strong inventory followed by the company's management as well as 
its low cash resources show that the central management does not manage to use its assets to the full in order to make the greatest possible profit.

Zara results: In contrast, at Zara the trend is upward. The company manages over the years to reduce its operating costs and maximize its net profits. The good management of the company is appeared in the upward and quite growing tendency of the index to present the profits created by its invested capital.

Return on Equity/ROE: This index shows the degree of utilization of equity while it presents the size of the profits created by the invested funds of the shareholders. ROE is a measure of financial return calculated by dividing net income by equity. Because equity equals a company's assets less debt, ROE could be considered as a return on net assets. Basically, ROE only measures the return on equity of the company excluding its liabilities. Thus, ROA is accountable for the debt of a company while this is not possible with the use of ROE (Talluri et al., 2013).

Bershka results: Regarding the results of Bershka, while the index starts with a relatively high percentage indicating the positive course of the company, the return on net assets decreases significantly.

Zara results: Zara, on the other hand, is on the rise. The return on equity is considered sufficient while the sharp increase of the index indicates that the company uses its resources efficiently to generate profits.

\subsection{Capital Structure Ratios}

Using the term leverage we mean the use of loan capital in order to increase the return on equity. It is a common position that the use of borrowed funds increases the expected return on equity of a business. Debt ratios show the way in which the company finances its total investments, that is its assets (Lynch \& Cross, 1995). More specifically, these indicators reflect whether a company finances its investments with loan funds as well as the possibility of defaulting on its loan obligations. Overall, these indicators try to access the long-term course of the business. The optimal capital structure will be the one that maximizes the company's profits with the least possible cost of capital and correlation between risk and return (Bragg, 2002).

\begin{tabular}{ccccc}
\hline CAPITAL STRUCTURE RATIOS BERSHKA & $\mathbf{3 1 / 0 1 / 2 0 1 7}$ & $\mathbf{3 1 / 0 1 / 2 0 1 8}$ & $\mathbf{3 1 / 0 1 / 2 0 1 9}$ & $\mathbf{3 1 / 0 1 / 2 0 2 0}$ \\
\hline EQUITY TO TOTAL LIABILITIES RATIO & 1.16 & 1.04 & 0.8 & 0.9 \\
EQUITY TO TOTAL ASSETS RATIO & $55.6 \%$ & $51 \%$ & $45.8 \%$ & $48.7 \%$ \\
EQUITY TO FIXED ASSETS RATIO & $90.45 \%$ & $83.2 \%$ & $65 \%$ & $68.9 \%$ \\
\hline
\end{tabular}

\begin{tabular}{ccccc}
\hline CAPITAL STRUCTURE RATIOS ZARA & $\mathbf{3 1 / 0 1 / 2 0 1 7}$ & $\mathbf{3 1 / 0 1 / 2 0 1 8}$ & $\mathbf{3 1 / 0 1 / 2 0 1 9}$ & $\mathbf{3 1 / 0 1 / 2 0 2 0}$ \\
\hline EQUITY TO TOTAL LIABILITIES RATIO & 0.85 & 0.76 & 0.84 & 0.87 \\
EQUITY TO TOTAL ASSETS RATIO & $45.9 \%$ & $43.4 \%$ & $45.9 \%$ & $47.8 \%$ \\
EQUITY TO FIXED ASSETS RATIO & $77.8 \%$ & $85.2 \%$ & $98.3 \%$ & $97.6 \%$ \\
\hline
\end{tabular}


Equity to Total Liabilities Ratio: This indicator shows the security that the company provides to its lenders while at the same time it expresses whether there is over-indebtedness as it expresses the relation between the equity to the total of the loan funds. If it is larger than the unit it shows that the management entity of the company participates with more funds than its creditors. The larger the relationship the greater security is provided to its creditors. It is noteworthy that most companies use a combination of liabilities and equity but there are some distinct advantages of equity financing for debt financing. The main one is that equity financing has no repayment obligation and provides additional working capital that can be used to grow a business. Companies usually have the choice of whether to seek financing with loans or equity. The choice often depends on which source of funding is most easily accessible to the company, its cash flow and how important it is to maintain control of the company to its main owners (Talluri et al., 2013).

Bershka results: The price of the index is high initially, specifically above the unit, which means that the shareholders of the company participate with more equity than its creditors. Although the index is gradually declining, its high levels indicate the necessary security that the company provides to its lenders.

Zara results: The Zara index fluctuates at a constant level, below the unit, which is an indication of over-indebtedness and relatively less security to creditors. Economic prudence sets some standards. In a large number of high or medium size programs can be applied an ideal ratio to liabilities 50:50 without this should be a standard.

Equity to Total Assets Ratio: This ratio is an investment leverage or solvency ratio that measures the amount of assets financed by owners' investments by comparing the company's total equity with total assets. This indicator highlights two important financial ideas for a sustainable business spirit. The first element shows how much of the total assets of the company belong entirely to investors while the second element shows conversely how the leverage of the company is with the debt. The high ratios show that there is no possibility of financial difficulty for the repayment of the company's liabilities (Delen et al., 2013).

Bershka results: The index is at a stable level, not particularly low, which indicates that there is not much pressure on it to repay its obligations and pay interest.

Zara results: Subsequently, the Zara index with a steady trend but relatively low indicators, may denote the company's policy regarding its source of funding.

Equity to Fixed Assets Ratio: Analyzing this ratio helps a company to fully understand the variable versus fixed costs and how it affects different parts of the business as well as the business as a whole. The course of the index reveals the policy pursued by a company regarding the way of financing its fixed assets. When the index rises, it means that the increase in fixed capital is financed to a greater extent by equity. On the contrary, a constantly decreasing index shows that the amounts for the increase of fixed capital have been obtained by loaning. 
Bershka results: The high levels of the index initially indicate that the fixed assets increase is financed mainly by equity. However, its declining course may indicate the company's borrowing to raise fixed assets.

Zara results: It is clear from the high indicators of Zara, that the increase of fixed assets is financed almost exclusively by equity.

\section{Conclusions}

The present study investigates the most two competitive companies of the Inditex group during the years 31/01/2017-31/01/2020 as a case study. The analysis focused mainly on the comparison of the brands with the respective competitive environment as well as on their development in terms of competitiveness and explanatory factors. The analysis made only in two companies of the group and in only a multinational group and this may be a limitation of this research. But the fact that these two firms have the largest market share in this group which consists of one of the largest groups in the Greek clothing and footwear industry can lead us to safe results for this sector.

The internationalization of the group has a positive relationship with efficiency. As companies invest in their expansion, experience and skills, so their competitiveness level is improved. The combination of techniques used in this study allowed us to find some standard facts that highlight some of the factors that could be considered relevant to the overall good picture of the brands as well as the success of the group.

Future research in the fast fashion industry could be aimed at extending the time period used in this venture and personalized analysis by brands and corporate markets. In conclusion, the possibility of a comparative financial study of multinational companies of the same scope with the company under study in the same industry would be prudent for further research.

\section{Conflicts of Interest}

The authors declare no conflicts of interest regarding the publication of this paper.

\section{References}

Bragg, D. (2002). Contemporary Vocational Models and Programs: What the Research Tells Us. New Directions for Community Colleges, 2002, 25-34. https://doi.org/10.1002/cc.50

Coelli, T., Rao, D. S. P., \& Battese, G. E. (1999). An Introduction to Efficiency and Productivity Analysis. Kluwer Academic Publishers. https://doi.org/10.1007/978-1-4615-5493-6

Delen, D., Kuzey, C., \& Uyar, A. (2013). Measuring Firm Performance Using Financial Ratios: A Decision Tree Approach. Expert System with Applications, 40, 3970-3983. https://doi.org/10.1016/j.eswa.2013.01.012

Dima, A., \& Dobrin, C. (2016). Globalization and the Competitiveness of the European Textile and Clothing Industry. The Annals of the University of Oradea, Economic 
Sciences, 124, 1102-1108.

Euske, K. J., \& Zander, L. A. (2005). History of Business Performance Measurement. In Encyclopedia of Social Measurement (Vol. 2, pp. 227-232). Elsevier.

http://hdl.handle.net/10945/43836

https://doi.org/10.1016/B0-12-369398-5/00473-4

Evans, J. R., \& Lindsay, W. M. (2008). The Management and Control of Quality (7th ed.). Thomson/South-Western.

Fischer, C., \& Schornberg, S. (2007). Assessing the Competitiveness Situation of EU Food and Drink Manufacturing Industries: An Index-Based Approach. Agribusiness, 23, 473-495. https://doi.org/10.1002/agr.20139

Ganiyu, R. A., Barbara, O. A., \& Paul, O. O. (2018). Trends in Business Performance Measurement: A Literature Analysis. International Journal of Social Sciences and Humanities Reviews, 8, 151-160.

Grigorakos, D. (2009). Financial Indicators of Companies (p. 20). https://dspace.lib.uom.gr/bitstream/2159/13387/2/GrigorakosMsc2009.pdf

Lucena, F. J., Aznar Díaz, I., \& Romero Rodríguez, J. M. (2020). Human Factor and Business Productivity: An Approach from the Analysis of Cross-Cutting Competences. Innovar, 30, 51-62. https://doi.org/10.15446/innovar.v30n76.85194

Lynch, R. L., \& Cross, K. F. (1995). Measure Up! Yardsticks for Continuous Improvement. Basil Blackwell.

Madushanka, K. H. I., \& Jathurika, M. (2018). The Impact of Liquidity Ratios on Profitability. International Research Journal of Advanced Engineering and Science, 3, 157-161.

Marques, A. D., Guedes, G., \& Fereira, F. (2017). Competitive Strategies in Fashion Industry: Portuguese Footwear Industry. IOP Conference Series: Materials Science and Engineering, 254, Article ID: 202006.

https://doi.org/10.1088/1757-899X/254/20/202006

Neely, A. (2002). Business Performance Measurement, Theory and Practice. Cambridge University Press. https://doi.org/10.1017/CBO9780511753695

Porter, M. (1985). Competitive Advantage: Creating and Sustaining Superior Performance. Simon and Schuster, Free Press.

Ramachandran, K., \& Madhumathy, M. (2016). A Study on Capital Structure and Financial Performance of Indian Textile Industry. International Journal of Management, 7, 313-322.

Scorrano, P., Fait, M., Maizaa, A., \& Vrontis, D. (2019). Online Branding Strategy for Wine Tourism Competitiveness. International Journal of Wine Business Research, 31, 30-50. https://doi.org/10.1108/IJWBR-06-2017-0043

Talluri, S., Kim, M. K., \& Schoenherr, T. (2013). The Relationship between Operating Efficiency and Service Quality: Are They Compatible? International Journal of Production Research, 51, 2548-2567. https://doi.org/10.1080/00207543.2012.737946

Tsoukatos, E., Psimarni-Voulgaris, F., Lemonakis, C., \& Vassakis, K. (2017). The Impact of R\&D and Information Technology on Innovation Performance of Greek SMEs. Global Business and Economics Review, 19, 521-535. https://doi.org/10.1504/GBER.2017.086602

Tuvadaratragool, S. (2012). The Role of Financial Ratios in Signaling Financial Distress: Evidence from Thai Listed Companies. Lismore. Southern Cross University.

Vrontis, D., Christofi, M., \& Katsikeas (2020). An Assessment of the Literature on CauseRelated Marketing: Implications for International Competitiveness and Marketing Re- 
search. International Marketing Review, 37, 977-1012.

https://doi.org/10.1108/IMR-07-2019-0202

Vrontis, D., Tardivo, G., Bresciani, S., \& Viassone, M. (2018). The Competitiveness of the Italian Manufacturing Industry: An Attempt of Measurement. Journal of the Knowledge Economy, 9, 1087-1103. https://doi.org/10.1007/s13132-016-0397-1

Zainudin, F., \& Hashim, A. (2016). Detecting Fraudulent Financial Reporting Using Financial Ratio. Journal of Financial Reporting and Accounting, 14, 266-278.

https://doi.org/10.1108/JFRA-05-2015-0053

Electronic sources: https://www.naftemporiki.gr http://www.businessdaily.gr 